Research Article

\title{
Investigating the Pavement Vibration Response for Roadway Service Condition Evaluation
}

\author{
Zhoujing Ye $\mathbb{D}^{1},{ }^{1}$ Yang Lu $\mathbb{D}^{2}{ }^{2}$ and Linbing Wang $\mathbb{D}^{3,4}$ \\ ${ }^{1}$ National Center for Materials Service Safety, University of Science and Technology Beijing, Beijing 100083, China \\ ${ }^{2}$ Civil Engineering Department, Boise State University, Boise, ID 83725-2060, USA \\ ${ }^{3}$ Joint USTB-Virginia Tech Lab on Multifunctional Materials, USTB, Beijing 100083, China \\ ${ }^{4}$ Virginia Tech, Blacksburg, VA 24061, USA \\ Correspondence should be addressed to Linbing Wang; wangl@vt.edu
}

Received 24 February 2018; Accepted 28 May 2018; Published 8 July 2018

Academic Editor: Yuqing Zhang

Copyright ( $\odot 2018$ Zhoujing Ye et al. This is an open access article distributed under the Creative Commons Attribution License, which permits unrestricted use, distribution, and reproduction in any medium, provided the original work is properly cited.

\begin{abstract}
Dynamic response of pavement provides service condition information and helps with damage prediction, while limited research is available with the simulation of pavement vibration response for evaluating roadway service condition. This paper presents a numerical model for the analysis of the pavement vibration due to the dynamic load created by a passing vehicle. A quarter vehicle model was used for the determination of the vehicle moving load. Both random and spatial characteristics of the load were considered. The random nonuniform moving load was then introduced in a 3D finite element model for the determination of the traffic-induced pavement vibration. The validated numerical model was used to assess the effects of dynamic load, material properties, and pavement structures on pavement vibration response. Numerical analyses showed that the vibration modes changed considerably for the different roadway service conditions. The vibration signals reflect the level of road roughness, the stiffness of the pavement materials, and the integrity of pavement structure. The acceleration extrema, the time-domain signal waveform, the frequency distribution, and the sum of squares of Fourier amplitude can be potential indexes for evaluating roadway service condition. This provides recommendations for the application of pavement vibration response in early-warning and timely maintenance of road.
\end{abstract}

\section{Introduction}

Pavement, the important transportation infrastructure, provides a smooth riding surface and basic load-bearing capacity for vehicles to travel on. Pavement structure will deteriorate under cyclic traffic loading and environmental factors. Early repair and maintenance scheduling increase the safe operation and in-service performance of pavement. This can be achieved through an accurate and consistent monitoring of dynamic response of pavement. Because the signal pattern can be analyzed to distinguish between deteriorated or cracked pavement section from the intact ones [1].

Stress-strain, displacement, and acceleration are the important monitoring parameters for the dynamic response of pavement. Due to the substantial improvement of acceleration sensing technologies, the microelectromechanical system (MEMS)-based acceleration sensors have been used in the monitoring of pavement vibration. The acceleration signals caused by the moving vehicle load were processed to obtain traffic information including vehicle speed, axle, weight, and traffic volume [2-5]. Moreover, by detecting the acceleration of pavement under specific wheel loadings and analyzing the vibration modes, it is possible to evaluate the pavement service condition.

Over the past several years, experimental studies have analyzed the pavement vibrations generated by vehicles to evaluate pavement service condition. Arraigada et al. [6] used accelerometers to measure pavement deflections due to traffic loads. Levenberg [7] inferred the pavement layer properties by using an integral electronic piezoelectric accelerometer. $\mathrm{Yu}$ and $\mathrm{Yu}[8]$ developed a cost-effective vibration-based system for preliminary evaluation of pavement conditions. Zhang et al. [9] analyzed time and frequency spectrums of vertical acceleration for the HMA 
slabs under different loading scenarios. However, the application of pavement vibration response in roadway service condition is still in the experimental stage.

On the contrary, theoretical and numerical studies have also been conducted. This can save large amount of laboratory efforts and time. The analyses considering the pavement vibration under dynamic vehicle load are widely adopted by many studies for various research purposes. Ju [10] developed a finite element (FE) model to investigate the characteristics of the building vibrations induced by adjacent moving trucks. Xu and Hong [11] investigated the effects of both a single heavy truck flow and a two-way traffic flow on building vibration. The results showed that traffic-induced ground vibrations disrupted high-tech facilities. Mhanna et al. [12] investigated the effect of the vehicle speed, the road unevenness, and the vehicle suspension system on the traffic-induced vibrations. Some recommendations were suggested for the reduction of these vibrations. Lak et al. [13] studied the relation between road unevenness, the dynamic vehicle response, and ground-borne vibrations. The influence of road unevenness on the free field vibrations was investigated. Wang et al. [14] tested four trackbed materials for their relative vibration attenuation capacities and studied the effect of different speed and weight of the passing train on the performance of the paving materials. Their purpose is to reduce the adverse effects of pavement vibration on the surrounding structures and vehicles, rather than to analyze the pavement vibration signals for evaluating the pavement service condition.

However, there are few studies to evaluate the pavement service condition through vibration simulation analysis. The assessment of roadway service condition is mainly reflected by the monitoring of stress, strain, and displacement. Saad et al. [15] examined the dynamic response of the fatigue strain at the bottom of the asphalt concrete layer and rutting strain at the top of the subgrade material by $3 \mathrm{D} \mathrm{FE}$ analyses. Alavi et al. [16] compared the dynamic strain data of intact and damaged FE model under moving tire loading. Features extracted from the dynamic strain data were used to detect the damage progression. Xue et al. [17] simulated the loading process by using finite-element analysis. The ratio between vertical stress and longitudinal horizontal strain was demonstrated to be related to the strength of pavements and can be used for the backcalculation of pavement modulus. Wu et al. [18] investigated the dynamic responses of stress and deflection at the critical load position by changing thickness, modulus of isolating layer, and the combination between the isolating layer and concrete slab. Patil et al. [19] studied the effects of vehicle-pavement interaction, pavement thickness, and soil parameters on the dynamic response of pavement to reveal their influences on pavement dynamic performances, including the effects of subbase module on maximum deflection.

Due to the improved MEMS-accelerometer technology, pavement vibration response can be used not only for traffic information monitoring but also has the potential to be used for evaluating the roadway service condition. This paper

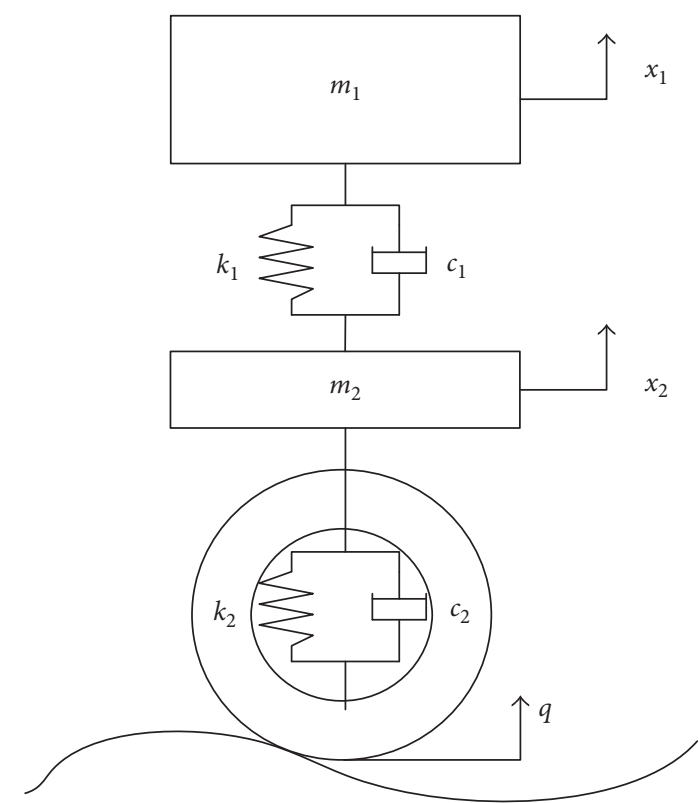

Figure 1: The quarter vehicle model.

presents a numerical model for the analyses in the timefrequency domain of the traffic-induced vibrations. The numerical modeling includes two stages. In the first stage, a quarter vehicle model is used for the determination in the time domain of the load due to road roughness. Both random and spatial characteristics of the load were considered. In the second stage, a 3D FE model of road is used to determine the pavement vibrations due to the load, which is calculated in the first stage. Then, the validated road model is used to evaluate the effects of dynamic load, pavement materials, and structure on pavement vibration response, so as to determine the potential evaluation index of roadway service condition.

\section{Numerical Model}

In the case of vehicle-road interaction, the prediction of the dynamic axle loads can be uncoupled from the solution of the road-pavement interaction problem due to the high stiffness of the road compared to the vehicle's suspension system or tire [20-23]. Therefore, the numerical modeling includes two stages: Firstly, the dynamic axle load resulting from pavement roughness was calculated by establishing a moving vehicle model composed of springs, dampers, and lumped mass. Then, the resulting axle dynamic load is used in a $3 \mathrm{D}$ numerical modeling for the determination of the pavement vibrations.

\subsection{Random Nonuniform Moving Load}

2.1.1. Time History. The quarter vehicle model, the half vehicle model, and the 3D vehicle model are the common vehicle models. But the quarter vehicle model is a widely used model because it can easily be used with personal computers to predict ride quality and pavement loading 
TABLE 1: The parameters of medium truck.

\begin{tabular}{lc}
\hline Vehicle parameters & Value \\
\hline$m_{1}(\mathrm{~kg})$ & 4450 \\
$m_{2}(\mathrm{~kg})$ & 550 \\
$k_{1}\left(\mathrm{~N} \cdot \mathrm{m}^{-1}\right)$ & 1000000 \\
$c_{1}\left(\mathrm{~N} \cdot \mathrm{s} \cdot \mathrm{m}^{-1}\right)$ & 15000 \\
$k_{2}\left(\mathrm{~N} \cdot \mathrm{m}^{-1}\right)$ & 1750000 \\
$c_{2}\left(\mathrm{~N} \cdot \mathrm{s} \cdot \mathrm{m}^{-1}\right)$ & 2000 \\
\hline
\end{tabular}

[24]. Although the quarter vehicle model does not allow to model pitch and roll effect on tire forces, the stochastic load can be simulated efficiently by using the quarter vehicle model when vehicle moves straight at a constant speed. Figure 1 shows the quarter vehicle model [25].

In this model, the suspension and nonsuspension masses corresponding to the one corner of the vehicle are denoted by $m_{1}$ and $m_{2}$, respectively. The suspension system is represented by a linear spring of stiffness $k_{1}$ and a linear damper of damping rate $c_{1}$. The tire is modeled by a linear spring of stiffness $k_{2}$ and a linear damper of damping rate $c_{2}$. The vertical displacements of suspension mass and nonsuspension mass are $x_{1}$ and $x_{2}$, respectively. The parameter values chosen for this study are shown in Table 1 [26].

According to the D'Alembert's principle, the motion differential equations of this vibration system are written as

$$
M \ddot{X}+C \dot{X}+K X=P
$$

where $M, C, K, X$, and $P$ are mass matrix, damping matrix, stiffness matrix, displacement matrix, and excitement matrix, respectively. They are written as

$$
\begin{aligned}
M & =\left(\begin{array}{cc}
m_{1} & 0 \\
0 & m_{2}
\end{array}\right), \\
K & =\left(\begin{array}{cc}
k_{1} & -k_{1} \\
-k_{1} & k_{1}+k_{2}
\end{array}\right), \\
C & =\left(\begin{array}{cc}
c_{1} & -c_{1} \\
-c_{1} & c_{1}+c_{2}
\end{array}\right), \\
P & =\left(\begin{array}{c}
0 \\
k_{2} q+c_{2} \dot{q}
\end{array}\right), \\
X & =\left(\begin{array}{l}
x_{1} \\
x_{2}
\end{array}\right),
\end{aligned}
$$

where $q$ is the displacement excitated by road roughness, which can be calculated as [27]

$$
\dot{q}(t)=2 \pi n_{0} \sqrt{G_{q}\left(n_{0}\right) v} \cdot w(t)-\omega_{0} q(t),
$$

where $w(t)$ is the time domain signal of Gaussian white noise with mean zero; $G_{q}$ is the road roughness coefficient; $v$ is the vehicle speed $(\mathrm{m} / \mathrm{s})$; and $n_{0}$ is the reference space frequency and $n_{0}=0.1 \mathrm{~m}^{-1}$. According to (1)-(7), the vehicle random dynamic load forcing on the pavement can be calculated as

$$
\begin{aligned}
F_{t} & =F_{\mathrm{d}}+G, \\
G & =\left(m_{1}+m_{2}\right) g, \\
F_{\mathrm{d}} & =k_{2}\left(x_{2}-q\right)+c_{2}\left(\dot{x}_{2}-\dot{q}\right),
\end{aligned}
$$

where $F_{t}$ is the vehicle random dynamic load; $G$ is the vehicle static load; $g$ is the acceleration of gravity; and $F_{\mathrm{d}}$ is the dynamic load applied by tires on pavement.

The quarter vehicle model was established in Matlab/Simulink. The speed was set to $10 \mathrm{~m} / \mathrm{s}$. According to the ISO 8608, the classes A, B, and C of road were obtained by adjusting the geometric mean of road roughness coefficient. The geometric mean of road roughness coefficient was set as 16 (i.e., $G_{q}=16$ ) when the road was a class A road [28]. Class A road represents high grade road, such as the highway, indicating that the surface of road is smoothness.

The sampling frequency of stochastic load was set as $1000 \mathrm{~Hz}$. Figure 2 shows the random dynamic load when the vehicle speed is $10 \mathrm{~m} / \mathrm{s}$ and road is class $A$ road.

When the vehicle travels on the class A road, the value of vehicle dynamic load is not constant due to the effect of road roughness, vehicle suspension system, vehicle speed, weight, and other factors. The value of vehicle dynamic load is random and fluctuates around $48 \mathrm{kN}$.

2.1.2. Spatial Distribution. In order to obtain the more actual pavement dynamic response, it is necessary to consider both random and spatial characteristics of the load. The actual tireto-pavement contact is surface to surface contact. Once the total tire force is known, the actual or more rational contact pressure distribution can be used by considering the actual configurations of the tires [29]. The actual tire-to-pavement contact is simplified as a rectangular area [30]. The rectangular area is affected by the tire pattern and the load value which varies with the space. Figure 3 shows a common style of tire pattern. The size of the rectangular area is $20 \mathrm{~cm} \times 18 \mathrm{~cm}$. There are five rib areas caused by the tire pattern [31].

When the vehicle moves straight at a constant speed, the ratio of load amplitude is about $1: 0.9: 0.5$ in center rib (R3), intermediate rib (R2, R4), and edge rib (R1, R5). Moreover, the spatial distribution of the vertical load can be simplified as a half-sine function in each rib area along the traffic direction [31, 32].

2.1.3. Moving Load. In order to simulate the movement of vehicle load, the secondary development of DLOAD subroutine was carried out based on FE software, ABAQUS, to simulate the random nonuniform moving load. A specified coordinate function $\operatorname{COORDS}(*)$ and a time function TIME(1) were used to define the loading area and implement the moving load. Equation (9) means the loading area moves at a constant velocity along the $X$ axis which is defined as traffic direction.

$$
X=\operatorname{COORDS}(1)-V \times \operatorname{TIME}(1)-X_{0},
$$




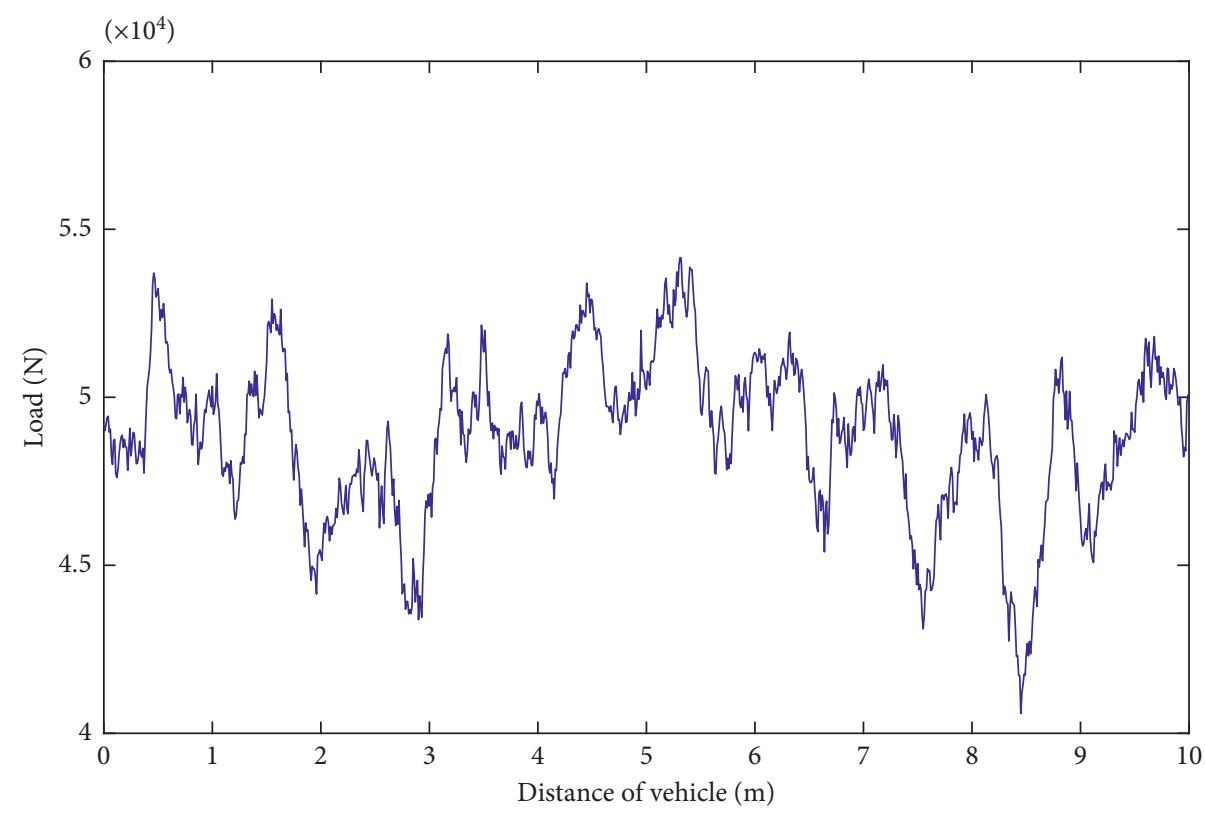

Figure 2: The random dynamic load when the vehicle speed is $10 \mathrm{~m} / \mathrm{s}$ and road is class A road.

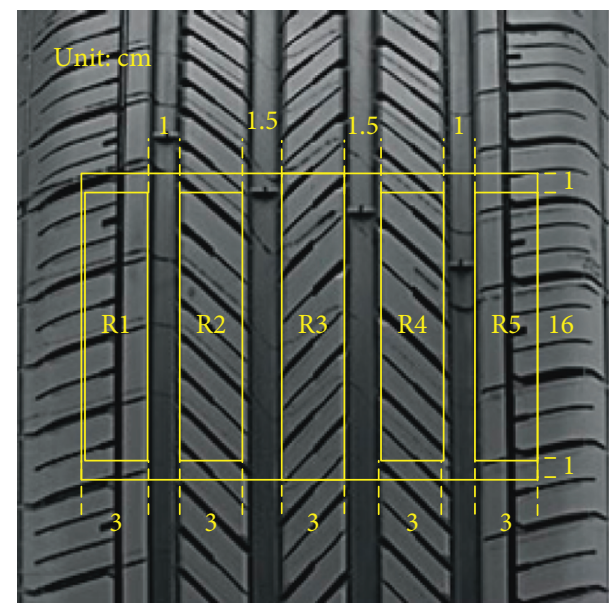

Figure 3: The actual tire-to-pavement contact.

where COORDS ( 1 ) is an array containing the $X$ coordinates of the load integration point; $X_{0}$ is initial coordinate $X$ value of load; $V$ is the vehicle speed; and TIME(1) is the current value of step time. Therefore, $X$ is an array containing the $X$ coordinates of the load integration point corresponding to the moving coordinate system.

Then the load in each rib by considering random and spatial characteristics was defined. Equation (11) means the spatial distribution of load at time $t$.

$$
\begin{aligned}
Y & =\operatorname{COORDS}(2)-Y_{0}, \\
\text { if } \operatorname{abs}(X) & \leq \frac{b}{2} \text { and } \operatorname{abs}(Y) \leq \frac{c}{2}, \\
\text { then } P(t) & =a * \frac{F(t)}{S} \times \sin \left(\frac{\pi}{b} \times X+\frac{\pi}{2}\right),
\end{aligned}
$$

where COORDS (2) is an array containing the $Y$ coordinates of the load integration point; the direction of $Y$ axis is perpendicular to the traffic direction; $Y_{0}$ is initial coordinate $Y$ value of load; abs $(X) \leq(b / 2)$ defines the length of the loading area; $\operatorname{abs}(Y) \leq(c / 2)$ defines the width of the loading area; $a$ is the ratio of load amplitude, which is set as 1 for R3, 0.9 for $\mathrm{R} 2$ and $\mathrm{R} 4$, and 0.5 for R 1 and R5; $b$ is the length of the load distribution along the traffic direction, which is set as $18 \mathrm{~cm}$ for R3, $16 \mathrm{~cm}$ for R1, R2, R4, and R5; $c$ is the width of the load distribution perpendicular to the traffic direction, which is set as $3 \mathrm{~cm}$ for each rib; $S$ is the actual contact area that is the sum of the areas from R1 to R5; $P(t)$ is the set of the surface pressure on the load integration point at TIME (1); and $F(t)$ is the random load produced by the quarter vehicle model at TIME(1).

The random nonuniform moving load is achieved by (9) and (11). The vehicle speed was set as $10 \mathrm{~m} / \mathrm{s}$, and the length of loading area was set as $3 \mathrm{~m}$. Therefore, the total time period was $0.3 \mathrm{~s}$. The increment time was set as $0.001 \mathrm{~s}$, which was consistent with the sampling frequency $(1000 \mathrm{~Hz})$ of stochastic load. Thus, the applied load can be assumed a continuous moving load if loading time is short enough.

2.2. Finite Element Model of Road. With the increased computational capabilities, the dynamic FE analysis of a pavement structure is a technique of considerable reduction in computation cost than before. A 3D FE model was developed to analyze the dynamic response of pavement under a moving truck tire loading.

2.2.1. Calculation Parameters. A model geometry of $9.0 \mathrm{~m} \times 6.5 \mathrm{~m} \times 4 \mathrm{~m}$ block was created to represent a typical four-layer roadway structure that referred to the structure of 


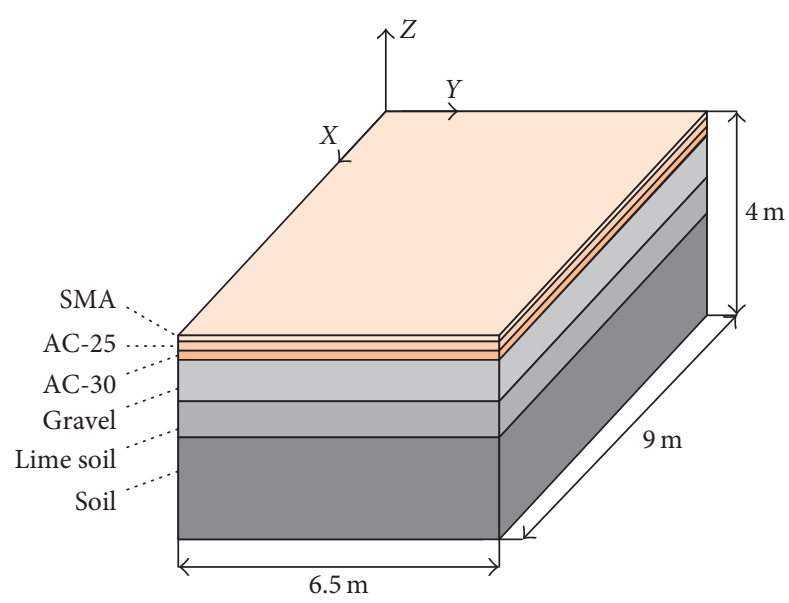

FIGURE 4: The 3D FE model of road.

TABLE 2: The material parameters of asphalt concrete pavement.

\begin{tabular}{lccccc}
\hline Material & $\begin{array}{c}\text { Thickness } \\
(\mathrm{cm})\end{array}$ & $\begin{array}{c}\text { Elastic } \\
\text { modulus } \\
(\mathrm{MPa})\end{array}$ & $\begin{array}{c}\text { Poisson's } \\
\text { ratio }\end{array}$ & $\begin{array}{c}\text { Density } \\
\left(\mathrm{kg} / \mathrm{m}^{3}\right)\end{array}$ & $\begin{array}{c}\text { Damping } \\
\text { ratio }\end{array}$ \\
\hline SMA16 & 4 & 1400 & 0.35 & 2400 & 0.05 \\
AC25 & 5 & 1200 & 0.35 & 2400 & 0.05 \\
AC30 & 7 & 1000 & 0.35 & 2400 & 0.05 \\
Gravel & 38 & 1300 & 0.25 & 2100 & 0.05 \\
Lime soil & 36 & 600 & 0.3 & 1900 & 0.05 \\
Soil & 200 & 50 & 0.4 & 1800 & 0.05 \\
\hline
\end{tabular}

Beijing 6th ring road. The information of this structure came from Dong's research [31]. Figure 4 shows the road model. The surface layer includes SMA, AC25, and AC30. The axes of $X, Y$, and $Z$ were set align with the longitudinal, transverse, and vertical direction, respectively. The driving direction was along the positive direction of $X$ axis.

Material parameters of each structure layer were determined by reference to the Specifications for Design of Highway Asphalt Pavement (Appendix E) [33], as shown in Table 2. The material parameters of AC30 were estimated by referring to the lower limit value of material parameters of AC25. The material viscosity was considered using Rayleigh damping for the energy dissipation through the medium. The damping ratio of pavement structure is generally between 0.02 and 0.2 and is set as 0.05 [34].

2.2.2. Constrain Condition and Mesh Generation. The three direction movements and rotations were restrained at the bottom of the subgrade on the model. The normal directions were restrained corresponding to the four sides of the model. In order to decrease the number of elements and reduce the cost of computation, the interface between subbase and subgrade was set as Tie constraint because of the small deformation on the subgrade. A Tie constraint ties two separate surfaces together so that there is no relative motion between them. The central area of the model surface was set as the loading area, so as to reduce the effect of boundary constraint on the simulation results.

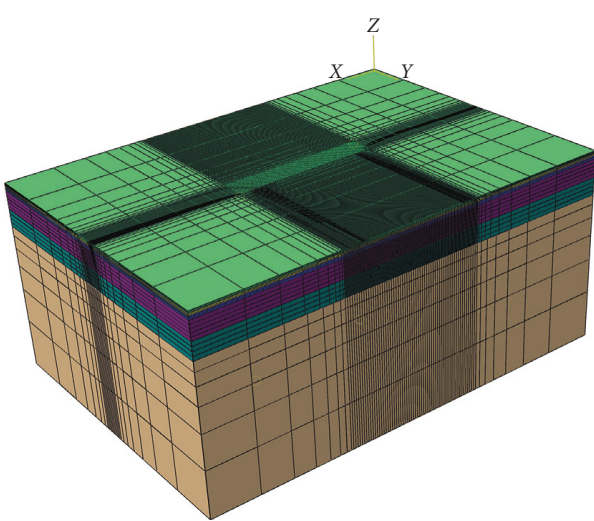

Figure 5: Mesh of the 3D FE model.

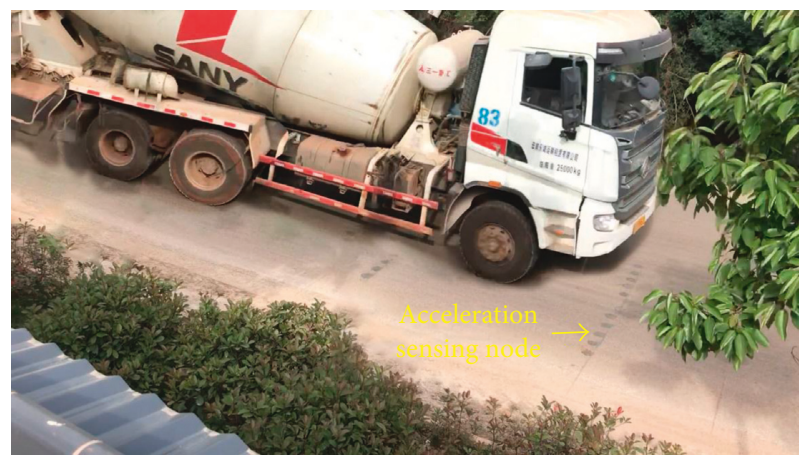

Figure 6: The field test on G320 road at Kunming.

Finer meshes were used in the loading area. The coarser meshes were used for the area far away from the loading area not only to ensure accuracy but also to improve calculation efficiency, as shown in Figure 5.

The road model was idealized with linear hexahedral element of type (C3D8R). The length and width of elements were $2 \mathrm{~cm} \times 2 \mathrm{~cm}$ in the loading area. The heights of elements were $2 \mathrm{~cm}, 2.5 \mathrm{~cm}$, and $3.5 \mathrm{~cm}$ for SMA, AC25, and AC30 layers, respectively.

2.3. Model Validation. In order to verify the road model, the simulation results were compared with the experimental data. The measured strain data came from Dong's research [31]. Dong et al. embedded the fiber Bragg grating (FBG) sensors on the Beijing Liuhuan Expressway. The FBG sensors were used to measure the vertical, transversal, and longitudinal strains of the pavement under the vehicle moving load. The measured vibration data came from our field test. The selfdeveloped acceleration sensing nodes were embedded on G320 road at Kunming to acquire the pavement vibration signal generated by vehicle moving load. The medium truck with a total weight of $25 t$ passed the monitoring area at a speed of $35 \mathrm{~km} / \mathrm{h}$. The depth of the accelerometer from the surface of road is $8 \mathrm{~cm}$. The pavement vibration signal excited by the front axle of this truck was chosen to compare with the simulated data, as shown in Figure 6.

Figure 7 shows the monitoring points. The point \#A was selected for strain and vibration response analysis. The point 


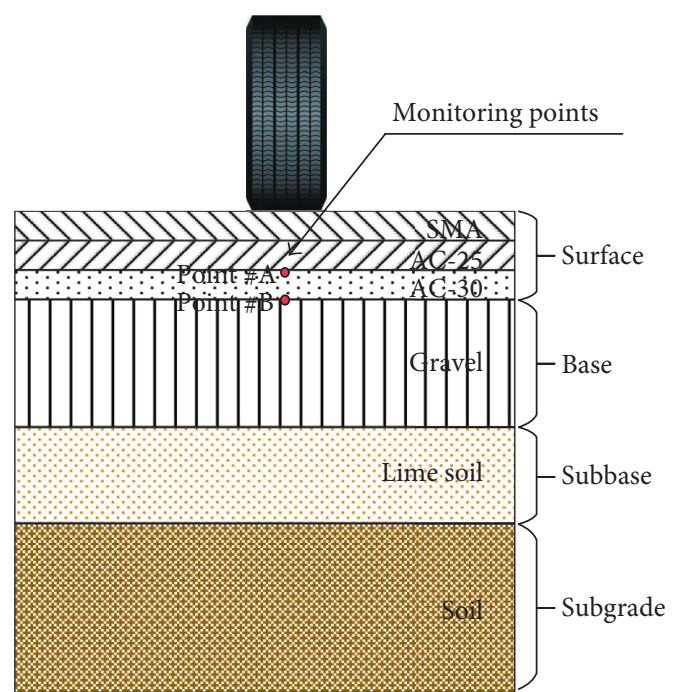

FIGURE 7: The monitoring points on the transverse section of the model center.

\#B was selected for strain response analysis. Figure 8 shows the comparison between simulated data and measured data.

In Figures $8(a)-8(\mathrm{c})$, the strain curves of simulation rebounded rapidly and did not have hysteresis after loading because the viscoelasticity of the asphalt pavement was not considered. However, the difference of maximum values between the simulated and measured data is just around $15 \%$. And the trend of strain curves matches well. The reasons for the deviations of strain curves were attributed to difference in the material parameters and random vehicle load adopted in real situation. However, the comparison still exhibits consistency between simulated and measured data and verifies that the numerical model used for FE simulation is coherent.

Figure 8(d) shows only one peak for the vibration because of one-wheel loading. The waveform initially falls and rises rapidly to form a significant peak and then falls again. Finally, it levels off. These characteristics are consistent with the measured data trend. However, the magnitude of simulated data is 10 times larger than the experimental data. This is because the simulated acceleration data can only be extracted from nodes of element by using ABAQUS program, and the nodes have a mass close to zero. However, the sensor node for pavement vibration monitoring has real mass. According to Newton's second law, the magnitude of the acceleration of an object is inversely proportional to the mass of the object. Therefore, the measured data were used as a reference, and the mass scaling factor was set to 10 . The mass-scaled simulation data match well with measured data. This model can be used to analyze road vibration response qualitatively under multiple conditions.

\section{Results and Discussions}

The validated FE model was adopted for various simulations to provide additional information on dynamic pavement performance, which might prove costly via laboratory tests only. The factors that would influence the dynamic responses of pavement under moving vehicle load are typically related with the external excitation from vehicle load, material properties, and geometric properties of pavement.

3.1. Influence of Dynamic Load. Vehicle parameters, speed, weight, and road roughness have influence on dynamic load of tire to pavement $[25,29,35]$. Therefore, the dynamic load coefficient (DLC) was used to represent the variation of the dynamic load, which can be calculated as

$$
\mathrm{DLC}=\frac{1}{F_{\mathrm{s}}} \sqrt{\frac{\sum_{i=1}^{N}\left(F_{i}-F_{\mathrm{s}}\right)^{2}}{N-1}} \times 100 \%,
$$

where $F_{i}$ is the vehicle random dynamic load at the $i$ th time step; $F_{\mathrm{s}}$ is the static load produced by vehicles; and $N$ is the total time step. The time step is $0.001 \mathrm{~s}$ and the total time is $0.3 \mathrm{~s}$.

The random dynamic load corresponding to different DLC was obtained by the quarter vehicle model, as shown in Figure 9. A larger value of DLC indicates the load fluctuates more dramatically.

By considering the actual tire-to-pavement contact, the random nonuniform load was applied to the road model to acquire pavement vibration response. The monitoring area was the surface of SMA layer below the tire center line, as shown in Figure 10.

Figure 11 shows the acceleration extrema of each node in the monitoring area. The acceleration extrema are the difference value between the maximum and the minimum acceleration in a loading time period.

In Figure 11, the variation of the acceleration extrema is random. The distribution range of acceleration extrema is larger when DLC is higher. The median values significantly increase with an increase in DLC, which is from $0.8 \mathrm{~g}$ to $1.33 \mathrm{~g}$, indicating that the number of larger acceleration extrema will grow if the dynamic load fluctuates more dramatically.

DLC increases when the surface condition of pavement declines. DLC increases with the increase of vehicle speed and the decrease of vehicle weight $[29,35]$. When the experimental vehicle passes the test road at the same speed, the vehicle weight and speed can remain the same. The distribution range of acceleration extrema is larger when DLC is higher. Therefore, the wider distribution range of acceleration extrema indicates the worst condition of road surface.

3.2. Influence of Surface Materials. Asphalt and cement concrete are the common materials of the pavement surface layer, and their material properties are different. Asphalt concrete is a flexible material while cement concrete is a rigid one. Therefore, the influence of material properties on the pavement vibration was analyzed by comparing asphalt and cement concrete. Table 3 shows the material parameters of the cement concrete [18]:

The vibration response was compared between asphalt and cement concrete pavements. The monitoring points \#1, $\# 2$, and $\# 3$ of asphalt concrete pavement were placed below 


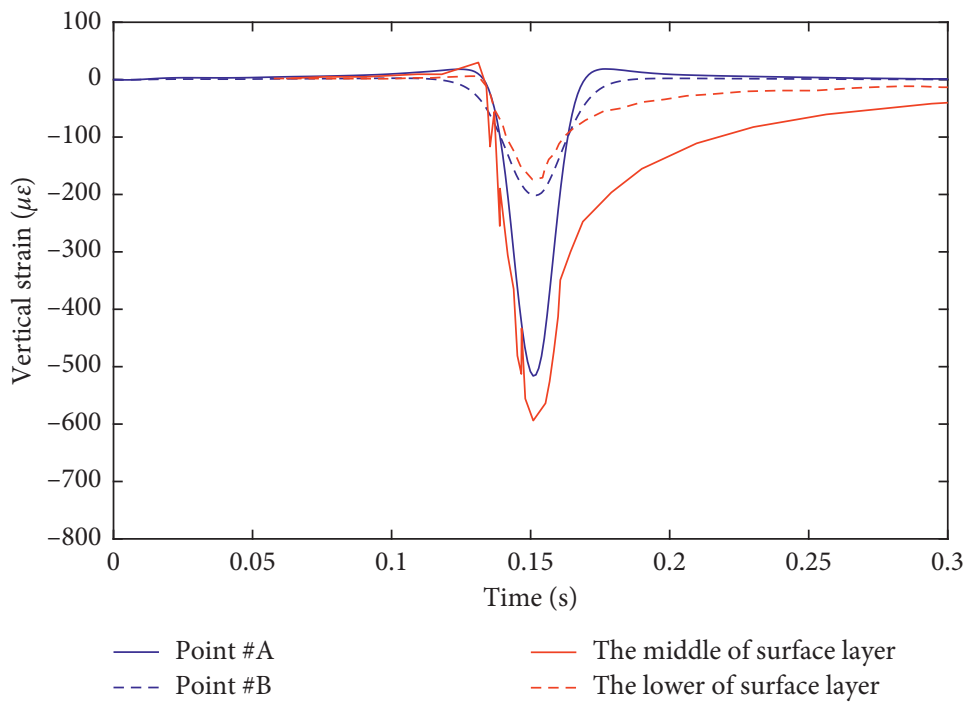

(a)

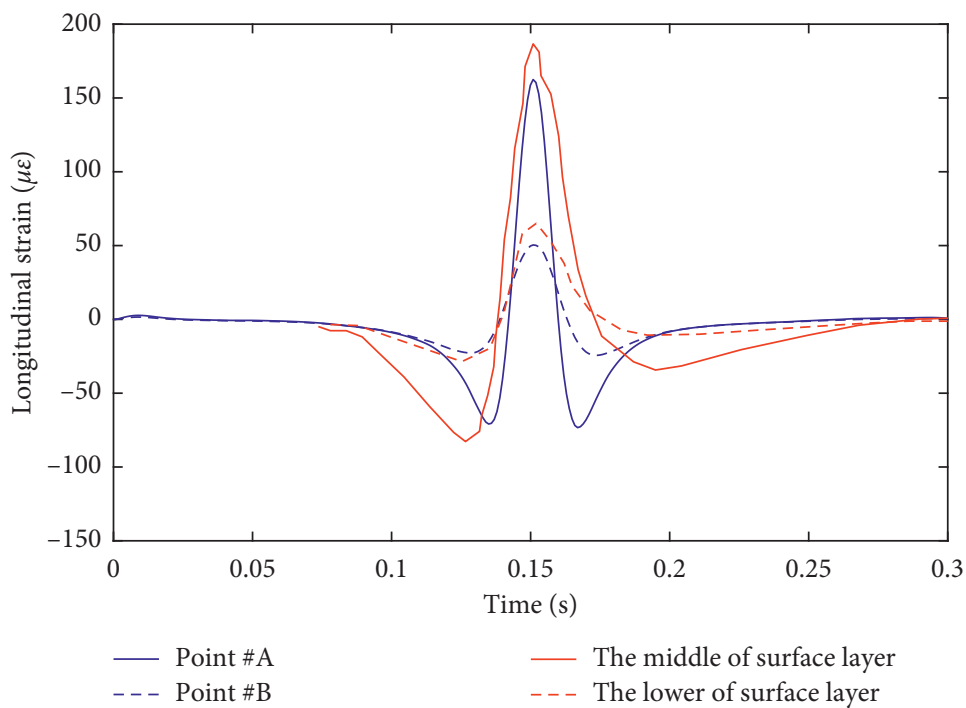

(b)

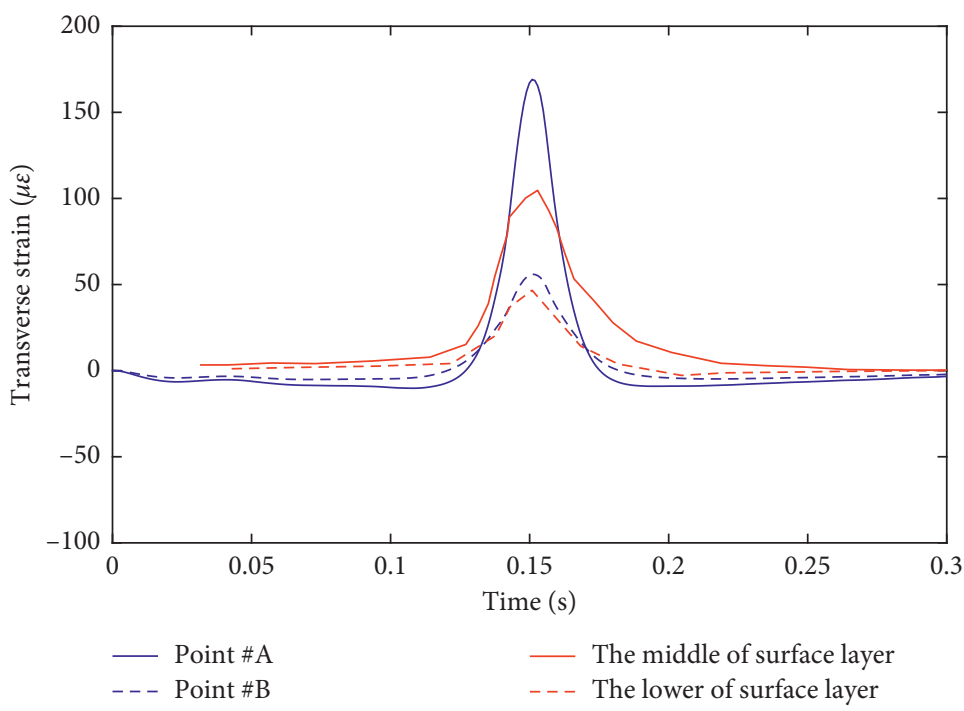

(c)

Figure 8: Continued. 

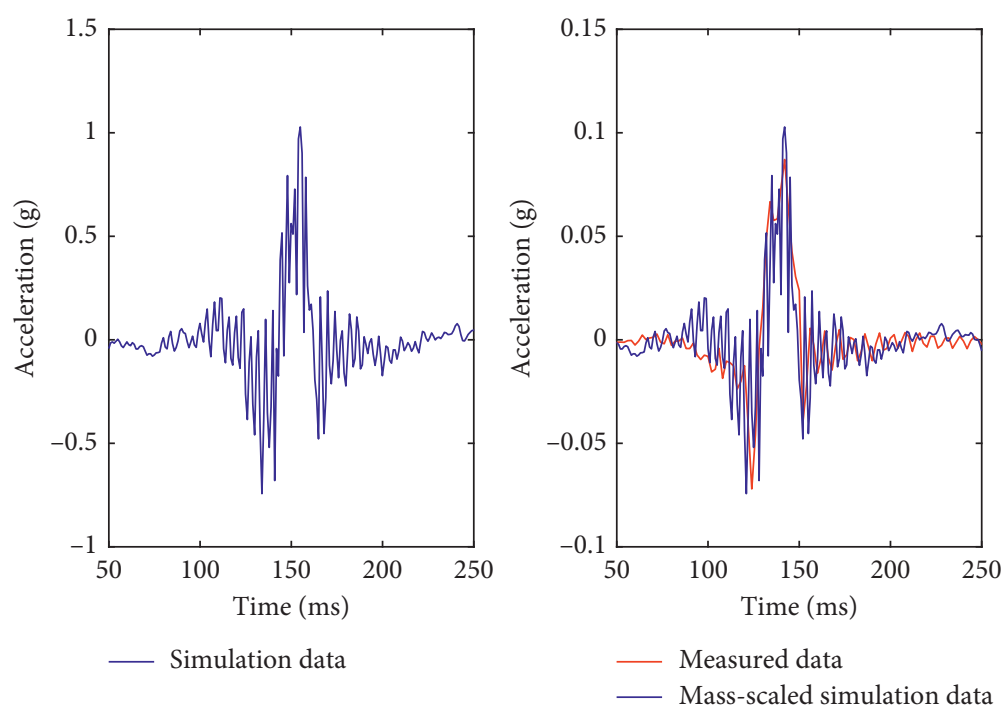

(d)

FIGURE 8: The comparison between simulated data and measured data (blue curves are simulated data and red curves are measured data). (a) The comparison of vertical strain. (b) The comparison of longitudinal strain. (c) The comparison of transverse strain. (d) The comparison of vertical acceleration.

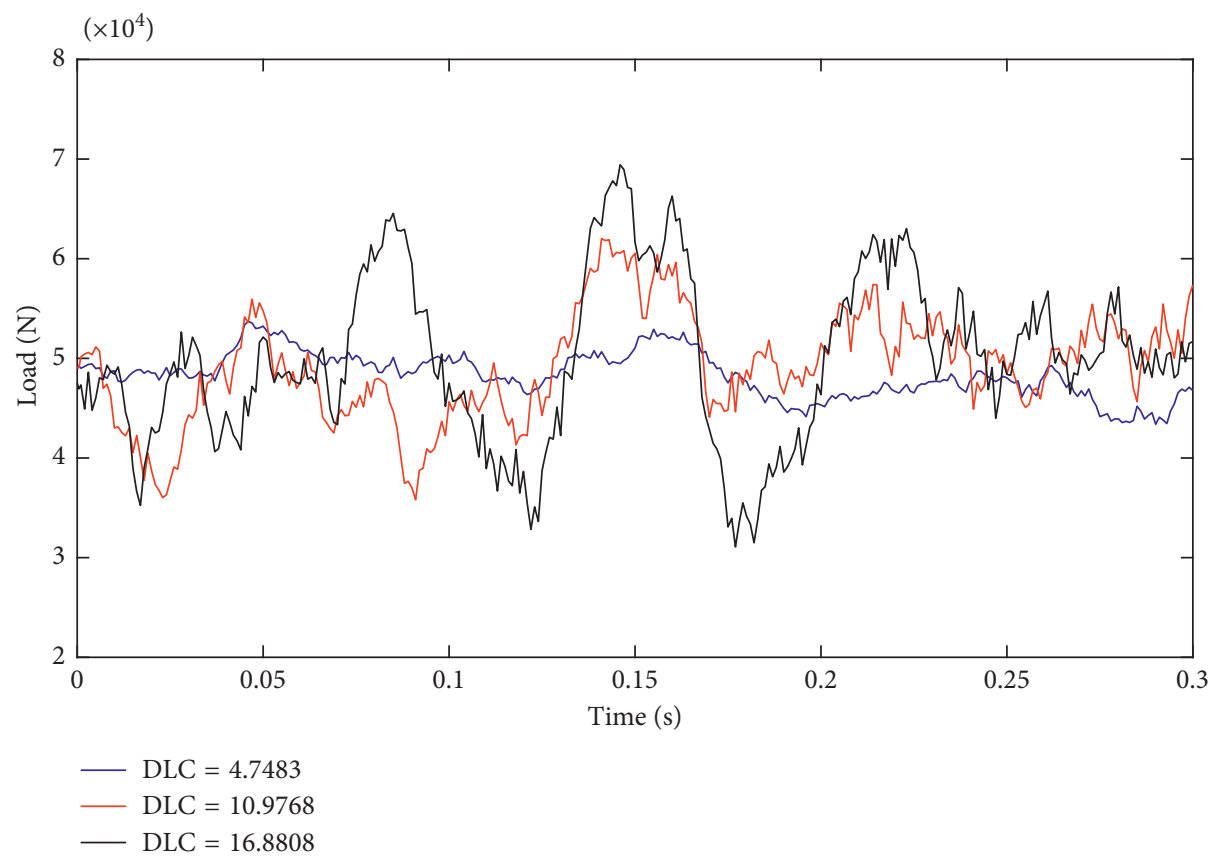

Figure 9: The random dynamic load corresponding to different DLC.

the tire, at the top of the SMA layer, the AC25 layer, and the AC30 layer, respectively. The coordinate of monitoring points in the model of cement concrete pavement was kept the same, as shown in Figure 12.

The dynamic load was applied to the road model when the road was class A road and the vehicle speed was $10 \mathrm{~m} / \mathrm{s}$. The vertical acceleration signals of different materials were compared at each monitoring point, as shown in Figure 13.

In Figures 13(a) and 13(b), the time-domain signal waveform can reflect information about the properties of the pavement materials, such as the degrees of flexibility and rigidness. For the asphalt concrete pavement, the vertical acceleration amplitude decreases significantly with an increase in the depth. The waveform tends to vibrate upward, which is due to the flexibility and integrality of the asphalt concrete pavement. The energy of downward vibration is absorbed by the flexible structures. On the contrary, for the cement concrete pavement, the waveform is almost symmetric, and the vertical acceleration amplitude has no obvious change at each point. This is due to a high strength of 


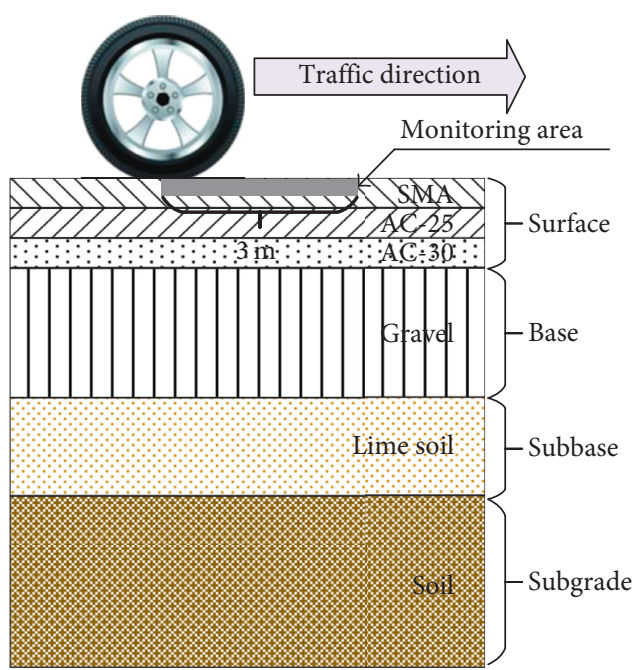

FIgURE 10: The monitoring area.

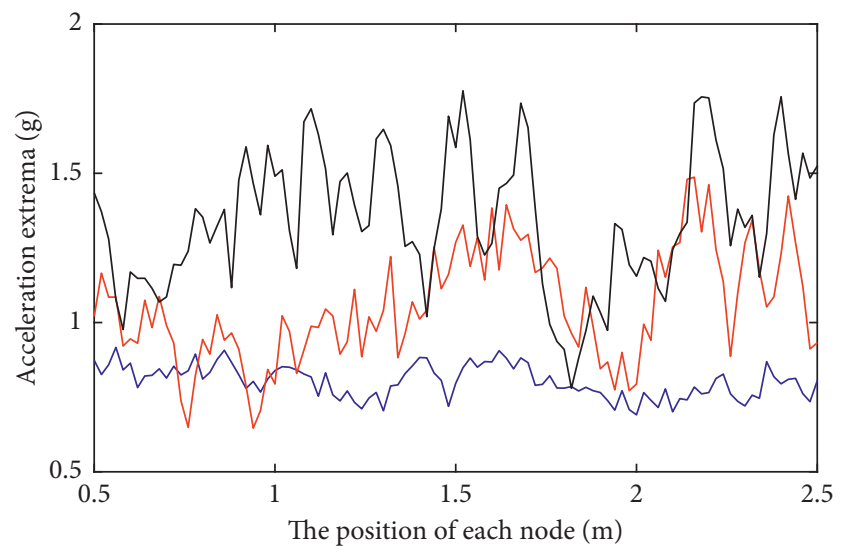

$\begin{aligned}- \text { DLC } & =4.7483 \\ - \text { DLC } & =10.9768 \\ \text { DLC } & =16.8808\end{aligned}$

(a)

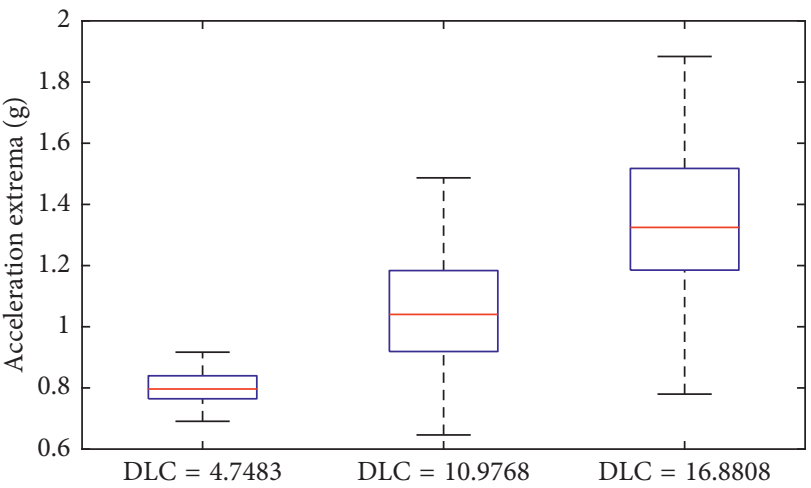

(b)

Figure 11: The distribution of acceleration extrema under different dynamic load. (a) The acceleration extrema of each node in the monitoring area. (b) The distribution box of acceleration extrema.
TABLE 3: The material parameters of cement concrete pavement.

\begin{tabular}{lccccc}
\hline Material & $\begin{array}{c}\text { Thickness } \\
(\mathrm{cm})\end{array}$ & $\begin{array}{c}\text { Elastic } \\
\text { modulus } \\
(\mathrm{MPa})\end{array}$ & $\begin{array}{c}\text { Poisson's } \\
\text { ratio }\end{array}$ & $\begin{array}{c}\text { Density } \\
\left(\mathrm{kg} / \mathrm{m}^{3}\right)\end{array}$ & $\begin{array}{c}\text { Damping } \\
\text { ratio }\end{array}$ \\
\hline $\begin{array}{l}\text { Cement } \\
\text { concrete }\end{array}$ & 16 & 31000 & 0.15 & 2400 & 0.05 \\
$\begin{array}{l}\text { Gravel } \\
\text { Lime }\end{array}$ & 38 & 1300 & 0.25 & 2100 & 0.05 \\
soil & 36 & 600 & 0.3 & 1900 & 0.05 \\
Soil & 200 & 50 & 0.4 & 1800 & 0.05 \\
\hline
\end{tabular}

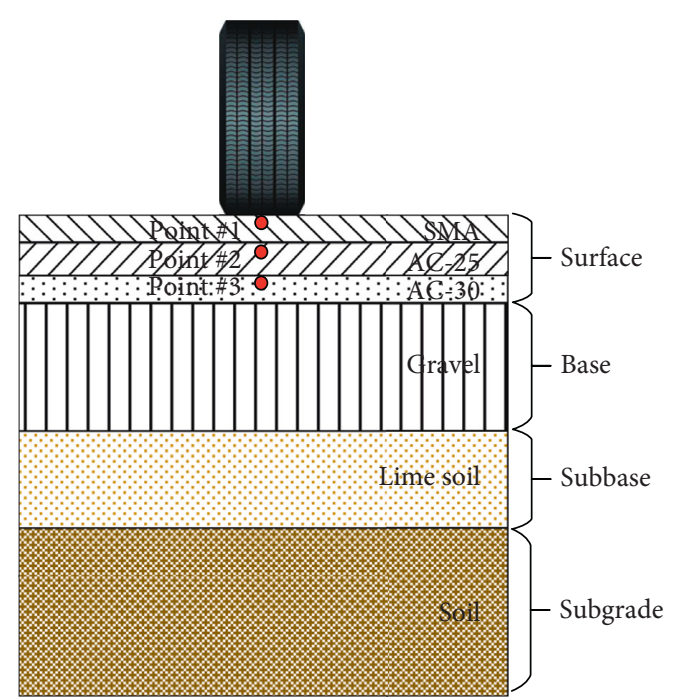

(a)

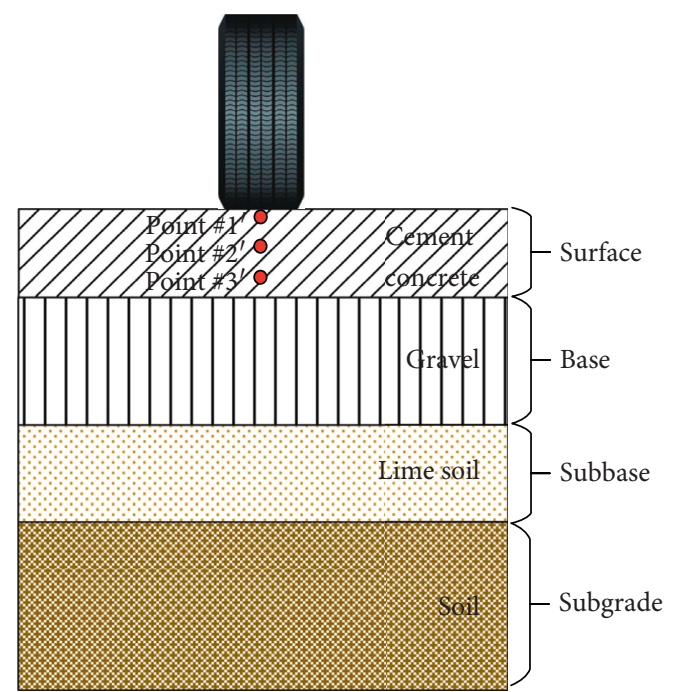

(b)

FIGURE 12: The monitoring points on the transverse section of the model center between asphalt and cement concrete pavements. (a) Asphalt concrete pavement. (b) Cement concrete pavement.

the cement concrete pavement. When the vehicle load acts on the surface layer of cement concrete pavement, it acts like a rigid plate body.

In Figures 13(c) and 13(d), the vibration frequency of asphalt concrete pavement is mainly within $50 \mathrm{~Hz}$. 


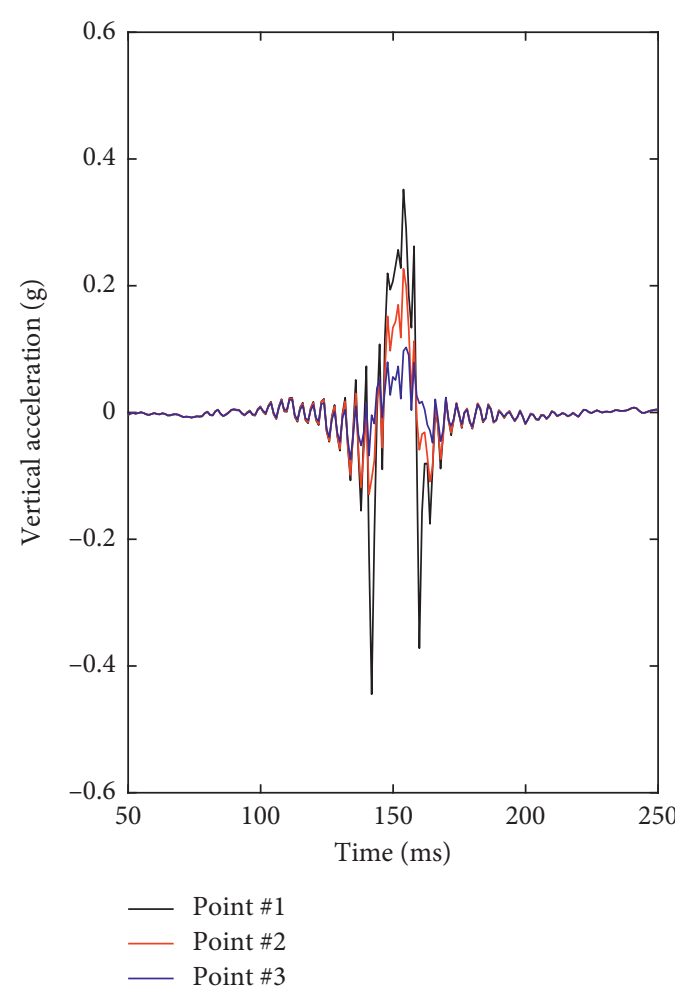

(a)

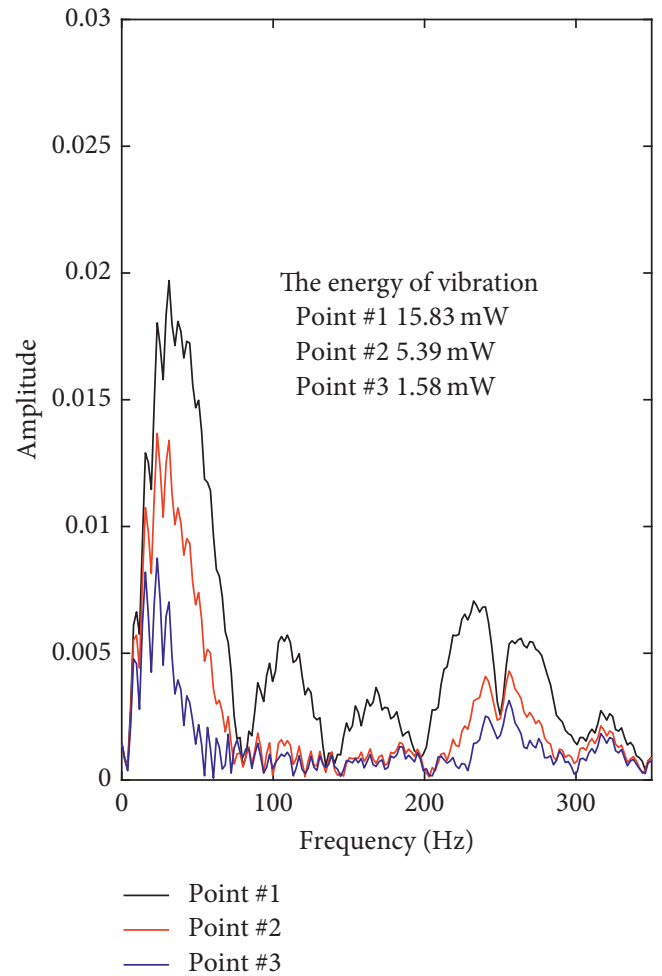

(c)

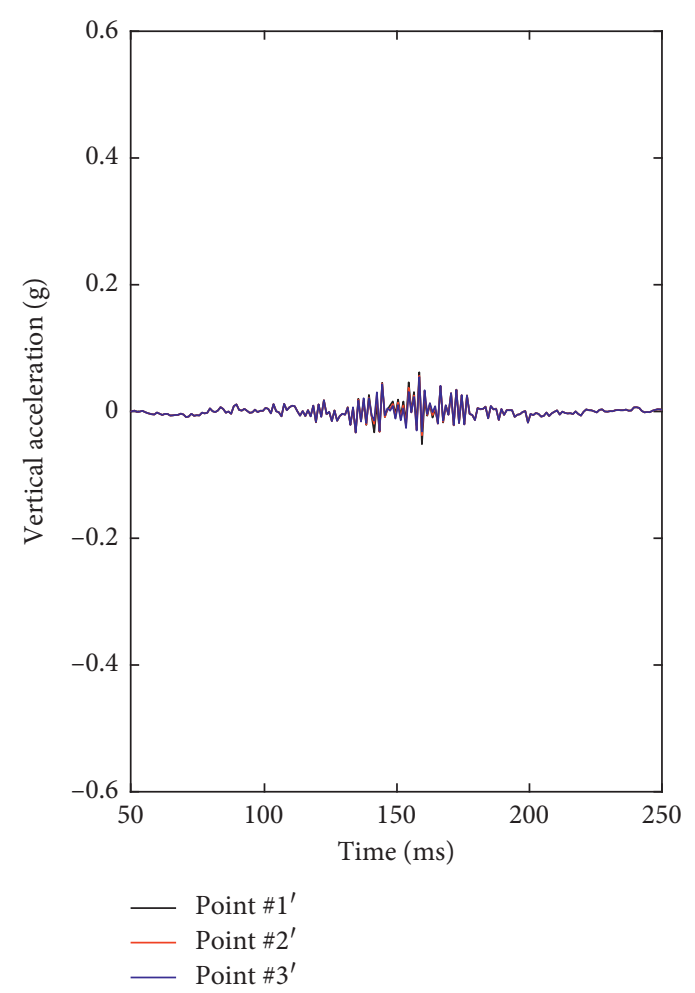

(b)

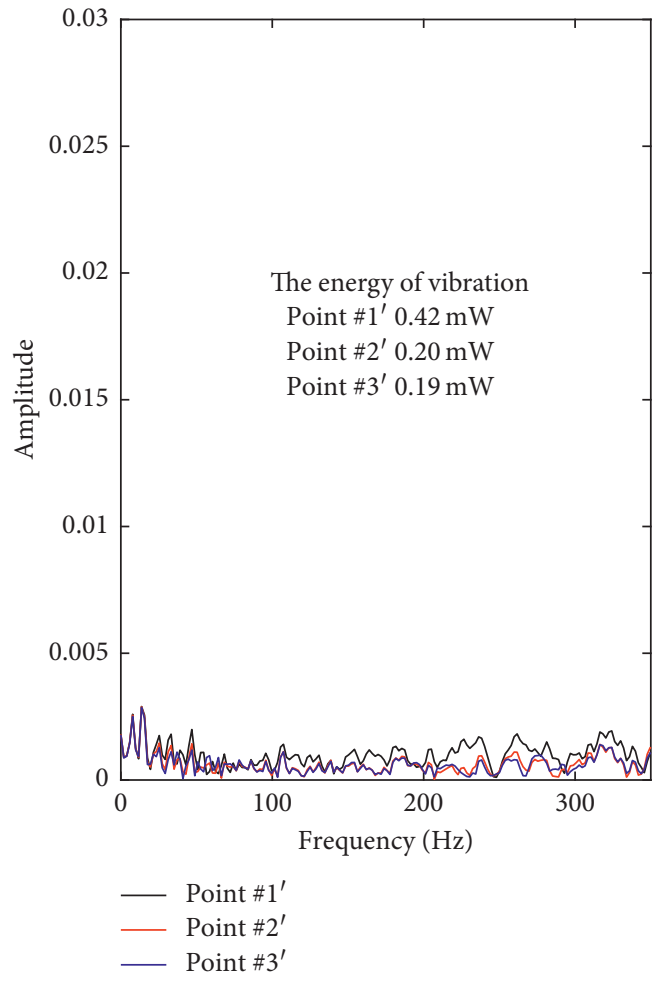

(d)

Figure 13: Comparison of vertical acceleration signals between asphalt and cement concrete pavements. (a) Time-domain vertical acceleration signals of asphalt concrete pavement. (b) Time-domain vertical acceleration signals of cement concrete pavement. (c) Frequencydomain vertical acceleration signals of asphalt concrete pavement. (d) Frequency-domain vertical acceleration signals of cement concrete pavement. 


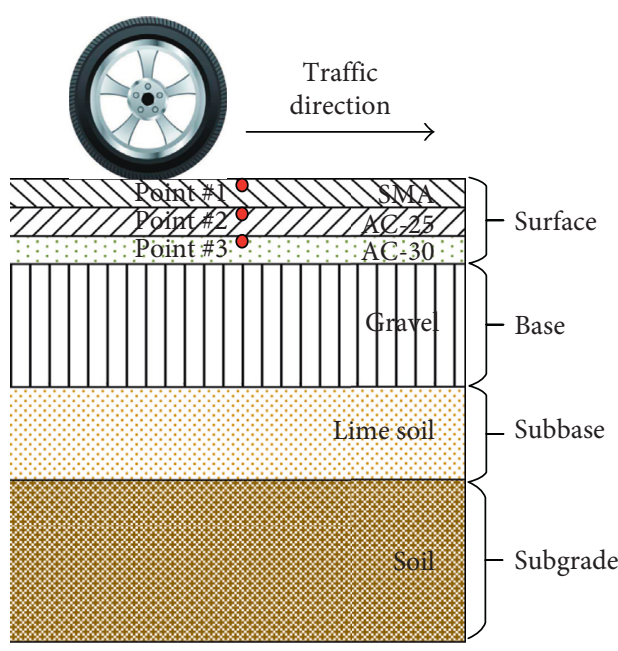

(a)

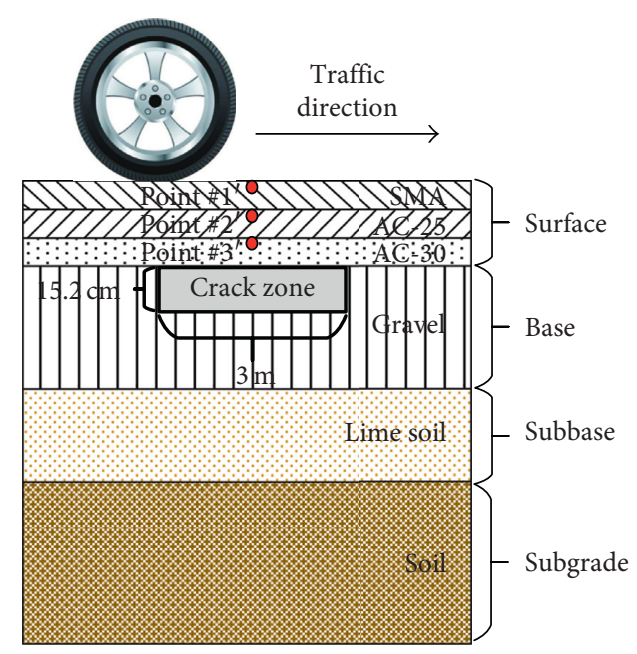

(b)

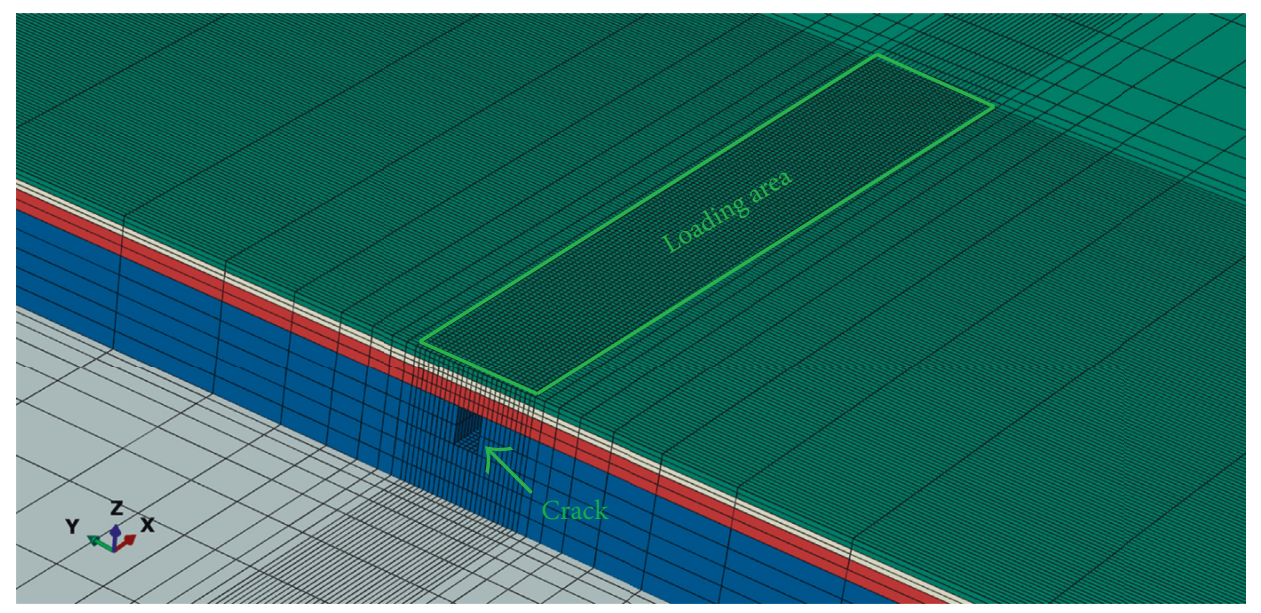

(c)

Figure 14: The monitoring points on the longitudinal section below the tire center line. (a) Intact pavement. (b) Damaged pavement. (c) Crack zone and loading area.

According to the Parseval's theorem, the energy of vibration can be identified as the sum of squares of Fourier amplitude. The energy of vibration becomes smaller with an increase in the depth. The energy is $15.83 \mathrm{~mW}$ at point $\# 1$, while it is only $1.58 \mathrm{~mW}$ at point \#3. On the contrary, the vibration frequency of the cement concrete pavement distributes normally. The energy of vibration is $0.42 \mathrm{~mW}$ at point $\# 1^{\prime}$ and $0.20 \mathrm{~mW}$ at point $\# 2$, which is far less than that of asphalt concrete pavement. The energy becomes smaller with an increase in the depth, but the decrease of energy is small. This is due to the good integer property of the surface layer of the cement concrete pavement. According to the law of conservation of energy, when the vehicle drives on the cement concrete pavement, the vehicle suspension system absorbs more energy, which results in the bumpiness of vehicle. But, the driving experience is good when the vehicle drives on the asphalt concrete pavement. However, the asphalt concrete pavement is susceptible to damage as it absorbs more energy.
3.3. Influence of the Structure Integrity. The pavement vibration response was compared between two cases: one with a road model that has no crack and the other with $3 \mathrm{~m}$-long and $10 \mathrm{~cm}$-wide by $15.2 \mathrm{~cm}$-deep crack located in the base layer, as shown in Figure 14. The crack area of the base layer was hollowed out according to the set size. The crack area was no need to mesh and define material parameter.

The vertical acceleration signals of different structure integrity were compared at each monitoring point, as shown in Figure 15.

In Figures 15(a) and 15(b), the vertical acceleration amplitude decreases as the depth increases for the noncracked model. However, for the cracked model, the vertical acceleration amplitude first decreases and then increases as the depth increases. The vertical acceleration amplitude of cracked model is maximum at point $\# 3^{\prime}$. Moreover, the vertical acceleration signals of cracked model have more prominent fluctuation characteristics under moving load, which is especially evident at point $\# 3^{\prime}$ near the crack zone. This is because the crack decreases the bearing capacity and stability of pavement structure. 

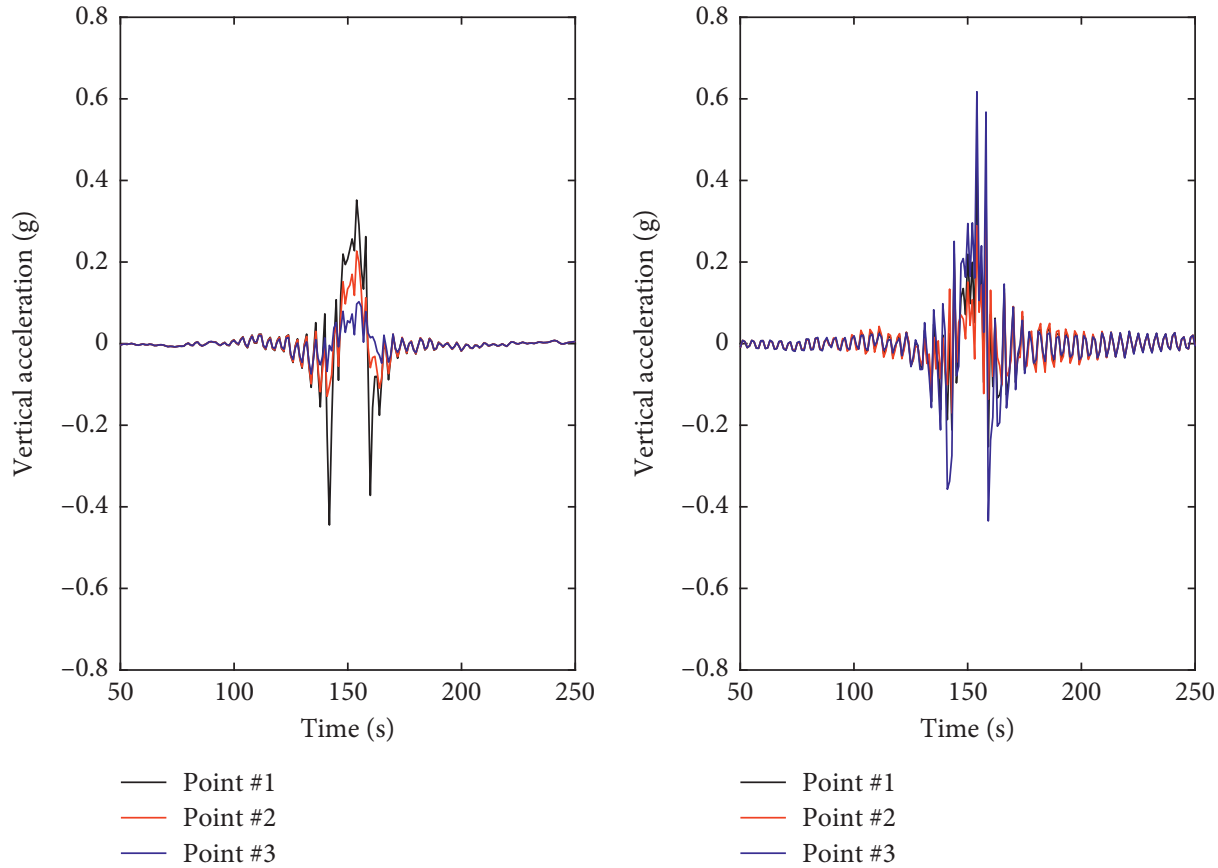

(a)

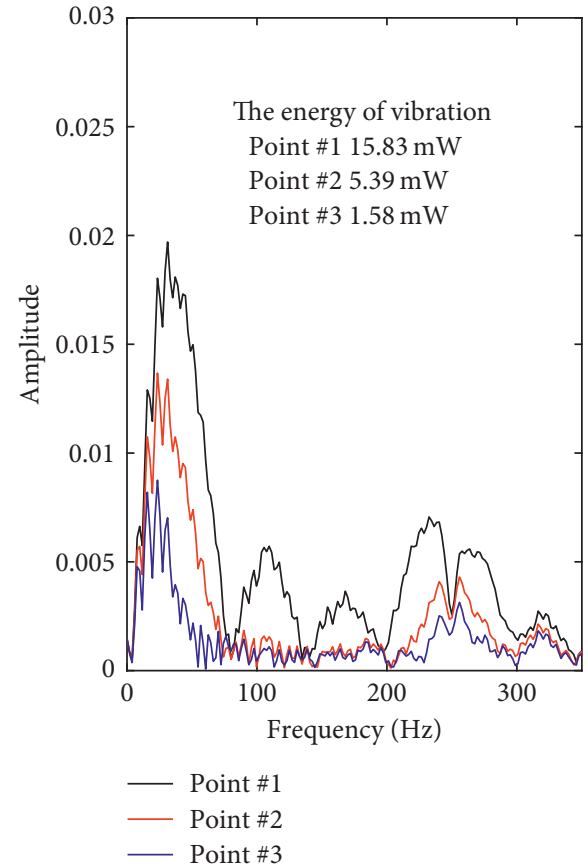

(b)

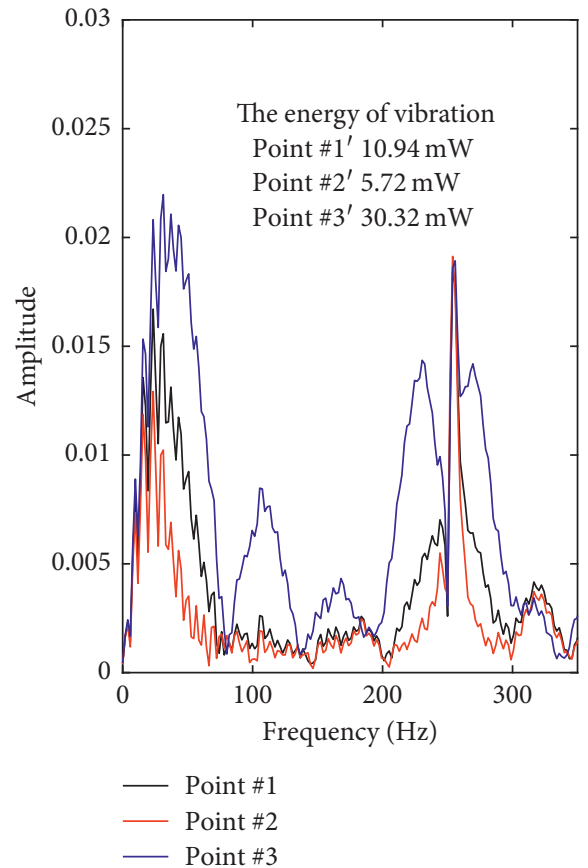

(c)

(d)

FIGURE 15: Comparison of the vertical acceleration signals of different structure integrity. (a) Time-domain vertical acceleration signals of asphalt concrete pavement with no crack. (b) Time-domain vertical acceleration signals of asphalt concrete pavement with crack. (c) Frequency-domain vertical acceleration signals of asphalt concrete pavement with no crack. (d) Frequency-domain vertical acceleration signals of asphalt concrete pavement with crack.

In Figures 15(c) and 15(d), the frequency distribution can reflect the information about the structure integrity of pavement. For the noncracked model, the vibration frequency of asphalt concrete pavement is mainly within $50 \mathrm{~Hz}$. However, when the cracking is present, the vibration frequency is not only below $50 \mathrm{~Hz}$ but also at $250 \mathrm{~Hz}$. This is due to the cracks that change the natural frequency of pavement structure. In addition, the energy of vibration becomes smaller with an increase in the depth for the noncrack model. However, for the cracked model, the damage areas have larger vibration energy compared with the intact areas. The energy of vibration is maximum at point $\# 3^{\prime}$ which 
reaches $30.32 \mathrm{~mW}$. This leads to further expansion of the crack and material failure. Under the same moving vehicle load, the total energy absorbed by damaged pavement, that is, $46.98 \mathrm{~mW}$, is higher than the total energy absorbed by intact pavement, that is, $22.80 \mathrm{~mW}$. This leads to a shorter service life of the damaged pavement.

\section{Conclusions}

This paper presented a numerical model for the analysis of the pavement vibrations resulting from vehicle moving load. The quarter vehicle model was used to determine the random load due to the road roughness. The random and spatial characteristics of the load were considered. Then the random nonuniform moving load was applied to the $3 \mathrm{D}$ FE model of the road, so as to acquire pavement vibration response. The vertical acceleration signals of various simulations were analyzed to find out the potential evaluation index of roadway service condition.

Numerical analyses showed that the vibration modes changed considerably for the different roadway service conditions. The vibration signals reflect the level of road roughness, the stiffness of the pavement materials, and the integrity of pavement structure. The acceleration extrema, the time-domain signal waveform, the frequency distribution, and the sum of squares of Fourier amplitude can be the potential index for roadway service condition evaluation. This provides recommendations for the application of pavement vibration response in early-warning and efficient maintenance of the road.

The numerical model can be used for analysis of the traffic-induced pavement vibration under different conditions, which is helpful for the evaluation of pavement service condition. However, there are still some improvements in a future study. The road model can be improved by considering the effect of ambient temperature and viscoelasticity of asphalt. And a further analysis could be done by doing the field test.

\section{Data Availability}

The data used to support the findings of this study are included within the supplementary information files.

\section{Conflicts of Interest}

The authors declare no conflicts of interest.

\section{Acknowledgments}

The research performed in this paper was supported by the National Key Research and Development Plan (no. 2017YFF0205602).

\section{Supplementary Materials}

The data file includes the data of Figure 2, Figure 8, Figure 9, Figure 11, Figure 13, and Figure 15. The references file includes important references that are written in Chinese and a software for reading CAJ documents. (Supplementary Materials)

\section{References}

[1] N. D. Beskou and D. D. Theodorakopoulos, "Dynamic effects of moving loads on road pavements: a review," Soil Dynamics and Earthquake Engineering, vol. 31, no. 4, pp. 547-567, 2011.

[2] Z. J. Ye, L. B. Wang, W. Xu, Z. Gao, and G. Yan, "Monitoring traffic information with a developed acceleration sensing node," Sensors, vol. 17, no. 12, p. 2817, 2017.

[3] R. Bajwa, R. Rajagopal, P. Varaiya et al., "In-pavement wireless sensor network for vehicle classification," in Proceedings of the 10th International Conference of Information Processing in Sensor Networks, pp. 85-96, IEEE, Chicago, IL, USA, April 2011.

[4] W. Ma, D. Xing, A. Mckee et al., "A wireless accelerometerbased automatic vehicle classification prototype system," IEEE Transactions on Intelligent Transportation Systems, vol. 15, no. 1, pp. 104-111, 2014.

[5] M. Stocker, P. Silvonen, M. Rönkkö, and M. Kolehmainen, "Detection and classification of vehicles by measurement of road-pavement vibration and by means of supervised machine learning," Journal of Intelligent Transportation Systems, vol. 20, no. 2, pp. 125-137, 2016.

[6] M. Arraigada, M. N. Partl, S. M. Angelone, and F. Martinez, "Evaluation of accelerometers to determine pavement deflections under traffic loads," Materials and Structures, vol. 42, no. 6, pp. 779-790, 2009.

[7] E. Levenberg, "Inferring pavement properties using an embedded accelerometer," International Journal of Transportation Science and Technology, vol. 1, no. 3, pp. 229-246, 2012.

[8] B. X. Yu and X. Yu, "Vibration-based system for pavement condition evaluation," in Proceedings of the 9th International Conference on Applications of Advanced Technology in Transportation, pp. 183-189, ASCE, Chicago, IL, USA, August 2006.

[9] Y. Zhang, C. Druta, L. Wang, H. Xiong, and W. Zhang, "Dynamic responses of asphalt concrete slab under cyclic wheel loading using acceleration spectrum analysis," Construction and Building Materials, vol. 152, pp. 134-144, 2017.

[10] S. H. Ju, "Finite element investigation of traffic induced vibrations," Journal of Sound and Vibration, vol. 321, no. 3-5, pp. 837-853, 2009.

[11] Y. L. Xu and X. J. Hong, "Stochastic modeling of trafficinduced building vibration," Journal of Sound and Vibration, vol. 313, no. 1-2, pp. 149-170, 2008.

[12] M. Mhanna, M. Sadek, and I. Shahrour, "Numerical modeling of traffic-induced ground vibration," Computers and Geotechnics, vol. 39, pp. 116-123, 2012.

[13] M. A. Lak, G. Degrande, and G. Lombaert, "The effect of road unevenness on the dynamic vehicle response and groundborne vibrations due to road traffic," Soil Dynamics and Earthquake Engineering, vol. 31, no. 10, pp. 1357-1377, 2011.

[14] J. C. Wang, X. Zeng, and R. L. Mullen, “Three-dimensional finite element simulations of ground vibration generated by high-speed trains and engineering countermeasures," Journal of Vibration and Control, vol. 11, no. 12, pp. 1437-1453, 2005.

[15] B. Saad, H. Mitri, and H. Poorooshasb, "Three-dimensional dynamic analysis of flexible conventional pavement foundation," Journal of Transportation Engineering, vol. 131, no. 6, pp. 460-469, 2005.

[16] A. H. Alavi, H. Hasni, N. Lajnef, and K. Chatti, "Continuous health monitoring of pavement systems using smart sensing 
technology," Construction and Building Materials, vol. 114, pp. 719-736, 2016.

[17] W. Xue, L. Wang, D. Wang, and C. Druta, "Pavement health monitoring system based on an embedded sensing network," Journal of Materials in Civil Engineering, vol. 26, no. 10, article 04014072, 2014.

[18] J. Wu, J. Liang, and S. Adhikari, "Dynamic response of concrete pavement structure with asphalt isolating layer under moving loads," Journal of Traffic and Transportation Engineering, vol. 1, no. 6, pp. 439-447, 2014.

[19] V. A. Patil, V. A. Sawant, and K. Deb, "3D finite-element dynamic analysis of rigid pavement using infinite elements," International Journal of Geomechanics, vol. 13, no. 5, pp. 533-544, 2013.

[20] M. J. Markow, J. K. Hedrick, B. D. Brademeyer et al., “Analyzing the interaction between dynamic vehicle loads and highway pavements," Transportion Research Record, no. 1196, pp. 161-169, 1998, http://onlinepubs.trb.org/Onlinepubs/trr/ 1988/1196/1196-016.pdf.

[21] D. Cebon, Interaction between Heavy Vehicles and Roads, Society of Automotive Engineers, Warrendale, PA, USA, 1993, ISBN: 1-56091-336-3.

[22] T. D. Gillespie, S. M. Karamihas, M. W. Sayers et al., "Effects of heavy-vehicle characteristics on pavement response and performance," Technical Report 353, National Cooperative Highway Research Program, Transportation Research Board, Washington, DC, USA, 1992, http://deepblue.lib.umich.edu/ bitstream/2027.42/996/2/58749.0001.001.pdf.

[23] M. S. Mamlouk, "General outlook of pavement and vehicle dynamics," Journal of Transportation Engineering, vol. 123, no. 6, pp. 515-517, 1997.

[24] K. B. Todd and B. T. Kulakowski, "Simple computer models for predicting ride quality and pavement loading for heavy trucks," Transportation Research Record: Journal of the Transportation Research Board, vol. 147, no. 3, pp. 137-150, 1989, http://onlinepubs.trb.org/Onlinepubs/trr/1989/1215/ 1215-016.pdf.

[25] L. Sun and T. W. Kennedy, "Spectral analysis and parametric study of stochastic pavement loads," Journal of Engineering Mechanics, vol. 128, no. 3, pp. 318-327, 2002.

[26] Z. Lu, Z. Hu, H. Yao, J. Liu, and Y. Zhan, "An analytical method for evaluating highway embankment responses with consideration of dynamic wheel-pavement interactions," Soil Dynamics and Earthquake Engineering, vol. 83, pp. 135-147, 2016.

[27] Y. J. Lu, S. P. Yang, S. H. Li, and L. Chen, "Numerical and experimental investigation on stochastic dynamic load of a heavy duty vehicle," Applied Mathematical Modelling, vol. 34, no. 10, pp. 2698-2710, 2010.

[28] ISO, Mechanical Vibration-Road Surface Profiles-Reporting of Measured Data, ISO 8608, International Organization for Standardization, Geneva, Switzerland, 1995.

[29] X. M. Shi and C. S. Cai, "Simulation of dynamic effects of vehicles on pavement using a 3D interaction model," Journal of Transportation Engineering, vol. 135, no. 10, pp. 736-744, 2009.

[30] M. N. S. Hadi and B. C. Bodhinayake, "Non-linear finite element analysis of flexible pavements," Advances in Engineering Software, vol. 34, no. 11-12, pp. 657-662, 2003.

[31] Z. J. Dong, Y. Q. Tan, and J. P. Ou, "Dynamic response analysis of asphalt pavement under three-directional nonuniform moving load," China Civil Engineering Journal, vol. 46, no. 6, pp. 122-130, 2013.
[32] H. Wang, I. L. Al-Qadi, and I. Stanciulescu, "Simulation of tyre-pavement interaction for predicting contact stresses at static and various rolling conditions," International Journal of Pavement Engineering, vol. 13, no. 4, pp. 310-321, 2012.

[33] JTG, Specifications for Design of Highway Asphalt Pavement, JTG D50, Bureau of Chinese Standard, Beijing, China, 2006.

[34] H. Y Li, Research on dynamics of pavement structure due to vehicle and pavement interaction, Ph.D. thesis, Beijing Jiaotong University, Beijing, China, 2011.

[35] Y. Q. Zhao, L. Bai, L. A. Liu et al., "Measurement and analysis of dynamic loading of trucks," Journal of Hunan University, vol. 41, no. 11, pp. 129-132, 2014. 


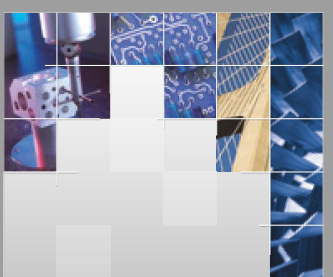

\section{Enfincering}
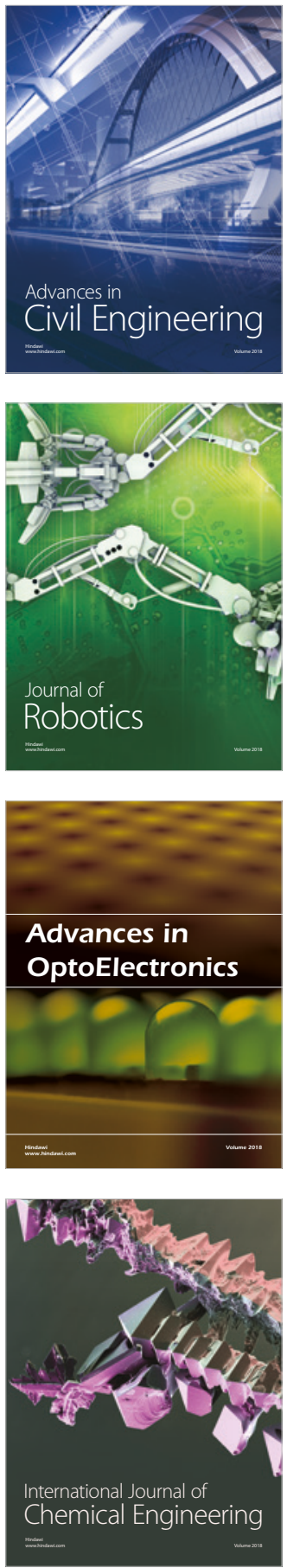

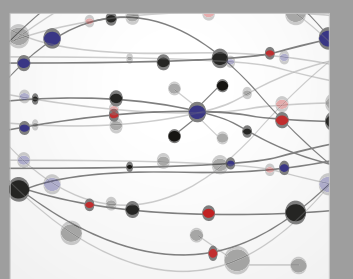

\section{Rotating \\ Machinery}

The Scientific World Journal

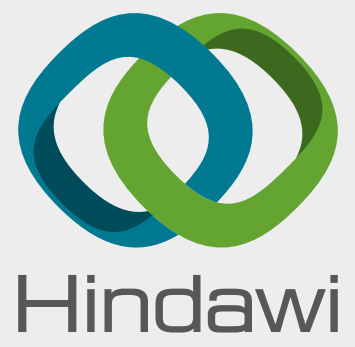

Submit your manuscripts at

www.hindawi.com
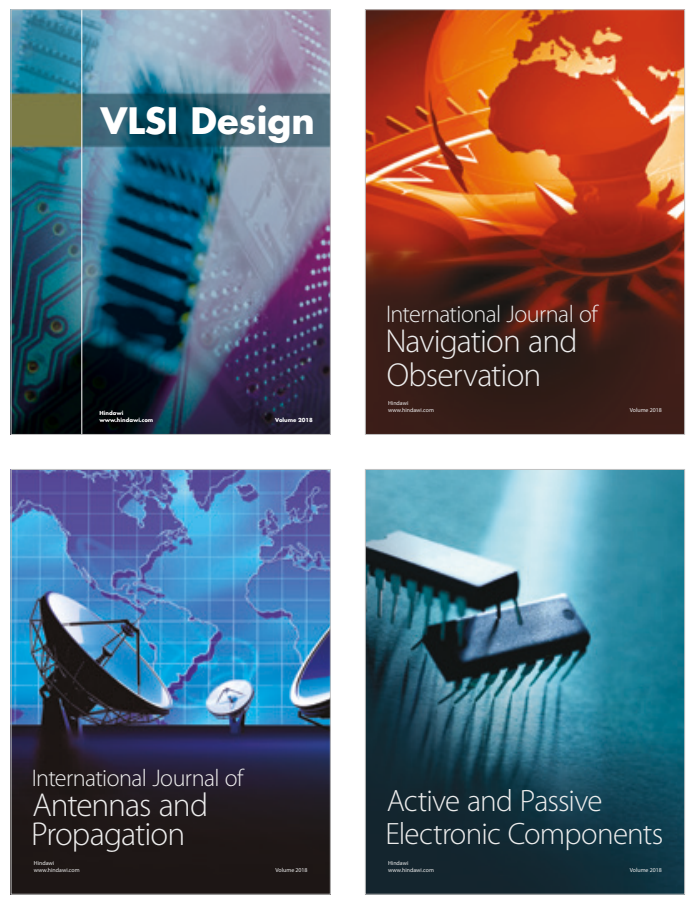
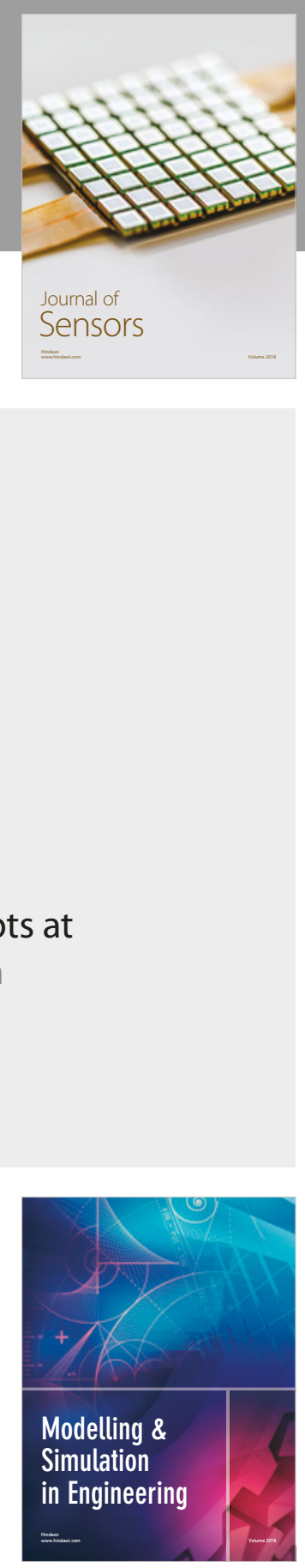

\section{Advances \\ Multimedia}
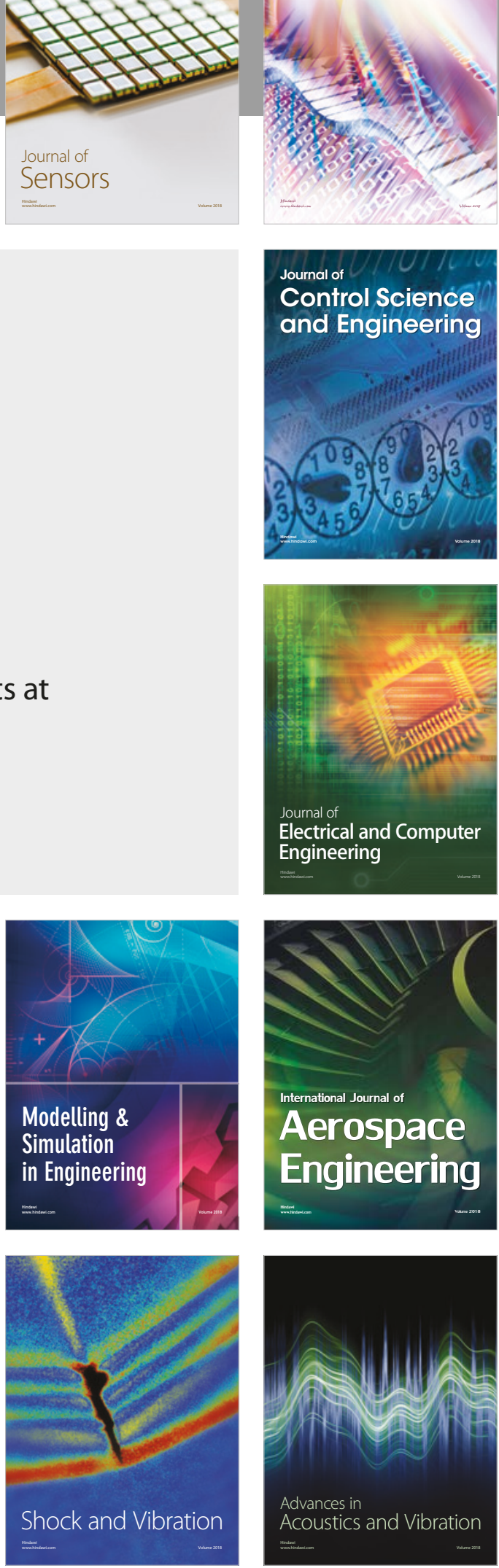